\title{
Designing an Instructional Publication on the Geology of Capitol Reef National Park
}

Kinsey Gayle Spiel

Brigham Young University

Follow this and additional works at: https://scholarsarchive.byu.edu/etd

Part of the Geology Commons

\section{BYU ScholarsArchive Citation}

Spiel, Kinsey Gayle, "Designing an Instructional Publication on the Geology of Capitol Reef National Park" (2016). Theses and Dissertations. 6063.

https://scholarsarchive.byu.edu/etd/6063

This Thesis is brought to you for free and open access by BYU ScholarsArchive. It has been accepted for inclusion in Theses and Dissertations by an authorized administrator of BYU ScholarsArchive. For more information, please contact scholarsarchive@byu.edu, ellen_amatangelo@byu.edu. 
Designing an Instructional Publication on the Geology of Capitol Reef National Park

\section{Kinsey Gayle Spiel}

A thesis submitted to the faculty of

Brigham Young University

in partial fulfillment of the requirements for the degree of

Master of Science

Thomas H. Morris, Chair

Scott M. Ritter

David D. Williams

Department of Geological Sciences

Brigham Young University

June 2016

Copyright (C) 2016 Kinsey Gayle Spiel

All Rights Reserved 


\author{
ABSTRACT \\ Designing an Instructional Publication on the Geology of \\ Capitol Reef National Park \\ Kinsey Gayle Spiel \\ Department of Geological Sciences, BYU \\ Master of Science
}

The wide variety of strata, structural features, and landscapes of Capitol Reef National Park result from its complex, yet discoverable history. Our task was to write and design an informative book on this complexity while making it engaging for the public. We approached the design of this book using Stufflebeam's (2007) CIPP model. The CIPP model uses both summative and formative evaluations in the categories of context, input, process, and product. It provides the framework to methodically investigate the value of a product and identify and correct less effective pedagogical and design elements during its development. We demonstrated the use of the CIPP model as we wrote and illustrated pages of our book.

Beginning with context, we identified our target audience, decided how we would provide a book that would serve this cohort, and made a plan for what we would accomplish with Exploring the Diverse Geology of Capitol Reef National Park. The input step involved understanding how to make our goals reality, especially concerning the design of the final book. We researched how the brain learns most effectively and incorporated those ideas into our book. We used principles developed by Clark and Mayer (2011) to reduce extraneous cognitive load. Research by James Hartley (1994) guided the instructional design and typography techniques. The process step helped us stay organized and follow our original plans. Finally, the product step enabled us and others to evaluate our product both formatively and summatively to make necessary alterations and plans for possibly future editions.

Keywords: Capitol Reef National Park, instructional design, CIPP model 


\section{ACKNOWLEDGEMENTS}

I express my sincere gratitude to my committee chair, Tom Morris, who made this project possible. You have helped me tremendously both academically and personally. Thank you also to my committee members, Scott Ritter and David Williams. Your insights and contributions were essential in this project. Thank you to all those who came on trips to Capitol Reef with me as "field assistants": Scott Meek, Alex Freeman, Megan Story, Mandilyn Sorensen and Alyssa Bowman. Thank you to Joe Huston for helping with photography. Thanks to Hannah Bonner for providing the beautiful paleogeographic reconstructions. Thank you to all those that sacrificed time to look through the book and let me interview them. I also appreciate Shirley Torgerson, Lori Rome, and all the other park rangers for their help and patience throughout this process. Thank you to all the previous geoscientists who have contributed to our understanding of the Capitol Reef area. And thank you to the BYU Geological Sciences Department for providing funding for trips to Capitol Reef.

I give my sincerest appreciation to my husband, Paul. Thanks for being excited about learning and for listening to me talk about rocks. Thanks to my parents, Jeff and Celeste, for encouraging me to progress in my education. Thanks to my siblings, Jordan and Alyssa, for being great friends. 


\section{TABLE OF CONTENTS}

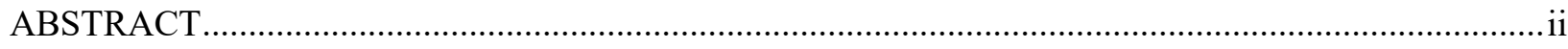

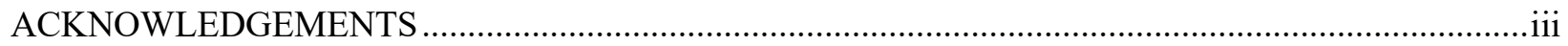

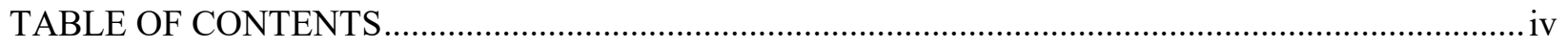

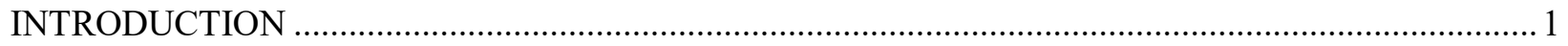

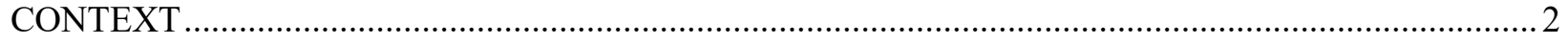

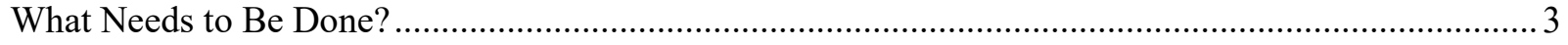

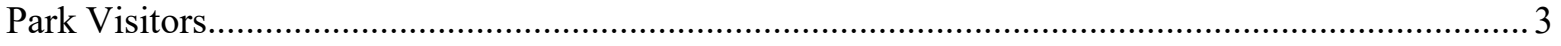

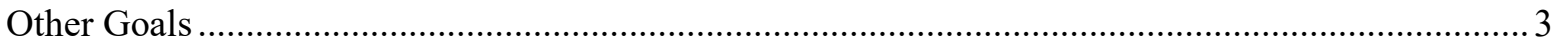

Were Important Needs Recognized and Addressed? ....................................................................... 4

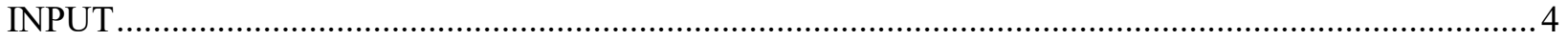

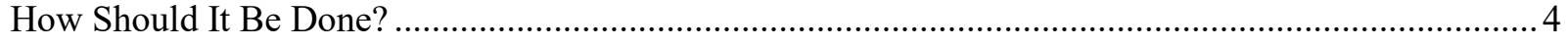

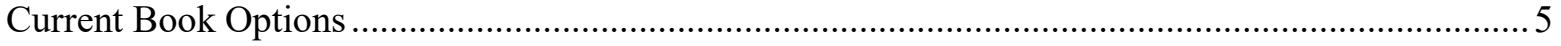

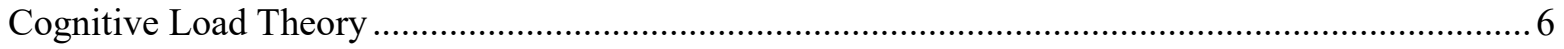

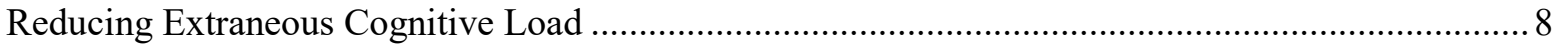

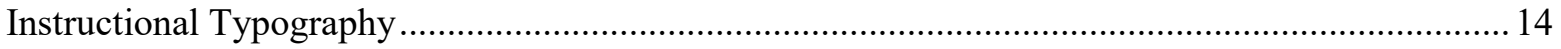

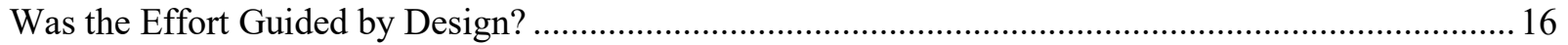

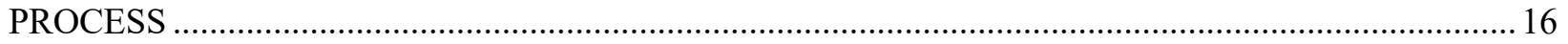

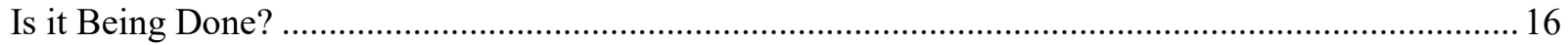

Was the Design Executed Competently and Modified as Needed? ..................................................... 16

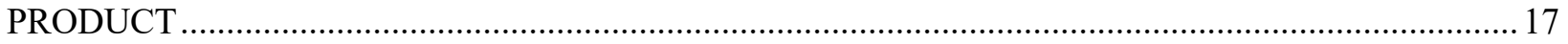

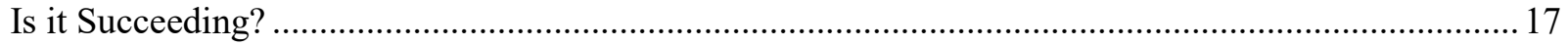

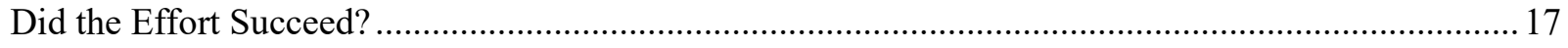

Size

Use

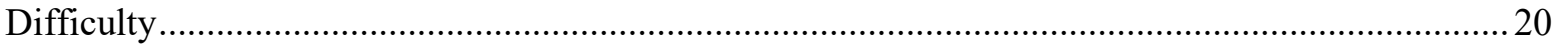

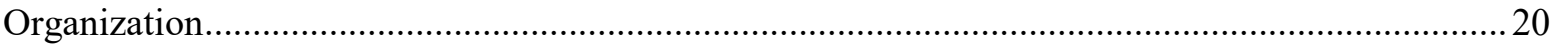

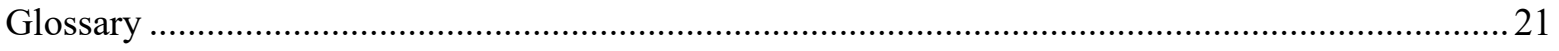

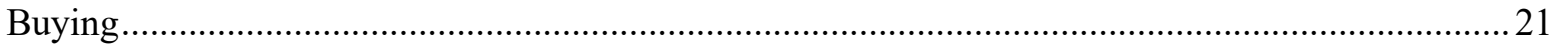

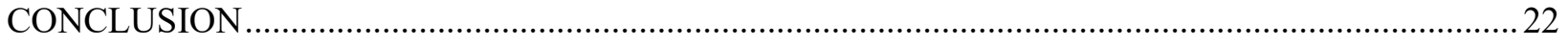

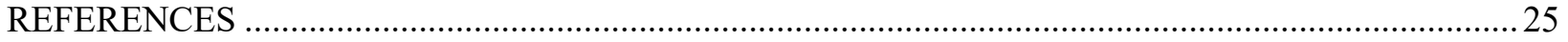




\section{INTRODUCTION}

Capitol Reef is among America's most geologically fascinating national parks. It exhibits diverse stratigraphy, complex structure, a variety of interesting landforms, and spectacular desert vistas. Visitors express curiosity about the formation and geologic history of this area. Park rangers are commonly asked about landscape formation, the variety of rock colors, the age of the rocks, and the geomorphology. However, there are currently no books sold in the visitor center specifically about the geology of Capitol Reef National Park. Lori Rome, the Chief of Interpretation, and Shirley Torgerson, the Executive Director of the Capitol Reef Natural History Association, have requested a book that will accurately and succinctly elucidate the geology of Capital Reef National Park. My goal was to develop an aesthetically pleasing book on the geology of Capitol Reef National Park that will enhance the public's appreciation of this singular park. Exploring the Diverse Geology of Capitol Reef National Park will provide visitors with an accurate resource that satisfies their geologic curiosity.

Throughout the progression of this project, I evaluated my goals, plans, actions and outcomes using the CIPP model. Evaluation is a way of methodically investigating the value of a product or program. The CIPP model approach enables the evaluator to improve throughout the process of developing a product by identifying and correcting problems in the process.

Stufflebeam (2007) formed the CIPP model in the 1960s as a means to increase accountability and improve teaching in U.S. school districts. Since then, the model has been adapted for broader areas and organizations. It is now a tool used in conducting both formative and summative evaluations in several systems such as government, community and economic development, philanthropy, organized religion, etc. It was a framework for evaluation in this project. CIPP is an acronym that stands for context, input, process, and product (Table 1.1). The evaluator guides 
formative evaluations with questions concerning the goals of the project, what plans are made, if those plans are happening, and if they are succeeding. These guide the evaluator in how to effectively move forward and make improvements as needed. Summative evaluations in the CIPP model essentially ask the evaluator if the goals, plans, actions, and outcomes of the project or product fulfill the intended purpose. This information is useful for future projects or revisions, and to individuals and organizations invested financially and otherwise.

\begin{tabular}{|l|l|l|l|l|}
\hline $\begin{array}{l}\text { Evaluation } \\
\text { Role }\end{array}$ & Context (Goals) & Input (Plans) & Process (Actions) & $\begin{array}{l}\text { Product } \\
\text { (Outcomes) }\end{array}$ \\
\hline Formative & $\begin{array}{l}\text { What needs to be } \\
\text { done? }\end{array}$ & $\begin{array}{l}\text { How should it be } \\
\text { done? }\end{array}$ & Is it being done? & Is it succeeding? \\
\hline Summative & $\begin{array}{l}\text { Were important } \\
\text { needs recognized } \\
\text { and addressed? }\end{array}$ & $\begin{array}{l}\text { Was the effort } \\
\text { guided by design? }\end{array}$ & $\begin{array}{l}\text { Was the design } \\
\text { executed } \\
\text { competently and } \\
\text { modified as needed? }\end{array}$ & $\begin{array}{l}\text { Did the effort } \\
\text { succeed? }\end{array}$ \\
\hline
\end{tabular}

Table 1.1 CIPP is an acronym for context, input, process, and product. Each category of the evaluation model asks both formative and summative questions, as shown above. (Stufflebeam and Shinkfield, 2007).

\section{CONTEXT}

Context evaluation formatively assesses what needs to be done to accomplish a goal. It identifies what steps need to take place, what challenges there may be, what services or expertise are available, and any programs or opportunities that could provide funding to achieve the objective. This step may include collecting information about the target audience, analyzing preliminary data, doing interviews or surveys, and analyzing the history of similar products. Summatively, the context step evaluates whether or not important needs were recognized and addressed. The context step of this project was an especially essential aspect. Knowing the audience, what type of book it would be, where the book would be used, etc. all played a role in knowing how to write and design the book. 


\section{What Needs to Be Done?}

An essential part of understanding the needs of this project was identifying our audience. In seeking information about the visitors to Capitol Reef, I found that surveying or asking questions of more than a handful of people would not be feasible because of legal limitations. However, I discovered Theresa Coble's "Visitor Voices Project" that conducted studies involving visitors in several national parks in 2005 and 2007-2008 (Coble et al., 2005 and Coble et al., 2009). This provided us with visitors' demographics, interests in visiting national parks, and experiences while there.

\section{Park Visitors}

In the "Visitor Voices Project," visitors 18 and older were given a written questionnaire that asked for information about intellectual and emotional connections to the park, interests, motivation to visit the park, previous experiences, general demographics, etc. These surveys showed that there were approximately equal numbers of men and women and most visitors were between the ages of 35 and 54. About a third of visitors had graduate degrees, and only a tenth had never attended college. Visitors stated that a ranger-led program was the most meaningful interpretive experience, followed by a brochure or other printed material. Most visitors said an interest in nature was a factor in their decision to visit the park. About half reported that their annual household income was between $\$ 50,000$ and \$150,000 (Coble et al., 2005 and Coble et al., 2009). From this, we determined that our target audience is middle-age, college-educated, curious about nature, and somewhat financially stable.

\section{Other Goals}

The context step also involved making a plan for the necessary steps that would follow. I made a plan to compile photographs, guide the writing of the text, make trips to Capitol Reef if 
necessary, and made a schedule of when I wanted to complete the chapters. I also identified challenges, which were mostly schedule-based. Dr. Morris and I also planned how to fund trips to the park and any other associated expenses.

\section{Were Important Needs Recognized and Addressed?}

Shirley Torgerson, of the Capitol Reef National History Association, and Lori Rome, Chief of Interpretation in Capitol Reef, asked Dr. Thomas Morris and I for a book that focused solely on the geology of the park. They requested a book that would be scientifically accurate, yet understandable to a geologic novice. Dr. Morris is a recognized expert on the geology of Capitol Reef National Park. His expertise combined with my education background and knowledge of instructional design enabled us to provide a publication that fit the park's needs. Using Coble's "Visitor Voices Project" (Coble et al., 2005 and Coble et al., 2009), we accounted for the approximate ages and education levels of park visitors and wrote our book to fit most of the visitors' education levels.

\section{INPUT}

Formatively, the input step involves deciding how objectives identified in the context step should be executed and asks, "How should it be done?" To achieve our goals, I evaluated current books in the park, completed coursework in instructional design and typography techniques, and made a plan for the organization of the book. Summatively the input step asks "Was the effort guided by design?" Upon completion we again looked over our process of book development (especially the design aspect) to ensure that we fulfilled our plans.

\section{How Should It Be Done?}


I used the input step to research what a book like Exploring the Diverse Geology of Capitol Reef National Park should include and how it should be designed to be most beneficial to the readers identified in the context step.

\section{Current Book Options}

Below is a summary of the purchase history of the current geology-based books sold in Capitol Reef National Park Visitor Center (Table 1.2). I used this information along with book reviews from amazon.com and goodreads.com to ascertain which qualities were most liked, disliked, understood, and misunderstood among visitors. Generally, readers enjoyed books that were organized meaningfully and designed simply. They appreciated diagrams and figures that were explained well and correlated with the text. Good photography and visually pleasant design made the books more enjoyable. Readers liked simple explanations and wording, but not so simple that they seemed juvenile. It was also important for readers to have detailed maps showing where key sites were located and how they could see them in person. Readers disliked authors that were not organized, expressed a lot of opinion rather than fact, and did not explain diagrams and illustrations. They also expressed a need for a basic overview of geologic concepts and vocabulary.

\begin{tabular}{|c|c|c|c|c|}
\hline Title & Author & $\begin{array}{l}\text { Current } \\
\text { Price }\end{array}$ & $\begin{array}{l}\text { Total } \\
\text { Sold }\end{array}$ & $\begin{array}{l}\% \text { of } \\
\text { total }\end{array}$ \\
\hline Geology Unfolded & $\begin{array}{l}\text { Thomas H. Morris, Scott } \\
\text { M. Ritter, And Dallin P. } \\
\text { Laycock }\end{array}$ & $\$ 10.95$ & 424 & $56.46 \%$ \\
\hline $\begin{array}{l}\text { Scenes of the Plateau } \\
\text { Lands and How They } \\
\text { Came to Be }\end{array}$ & William Lee Stokes & $\$ 4.95$ & 67 & $8.92 \%$ \\
\hline Pages of Stone & $\begin{array}{l}\text { Halka Chronic and Lucy } \\
\text { M. Chronic }\end{array}$ & $\$ 19.95$ & 44 & $5.86 \%$ \\
\hline $\begin{array}{l}\text { The Field Guide to } \\
\text { Geology }\end{array}$ & David Lambert & $\$ 16.95$ & 38 & $5.06 \%$ \\
\hline Hiking the Southwest's & Ralph Lee Hopkins & $\$ 18.95$ & 34 & $4.53 \%$ \\
\hline
\end{tabular}




\begin{tabular}{|c|c|c|c|c|}
\hline \multicolumn{5}{|l|}{ Geology } \\
\hline $\begin{array}{l}\text { Geology Underfoot in So } \\
\text { Utah }\end{array}$ & $\begin{array}{l}\text { Richard L. Orndorff and } \\
\text { Robert W. Wieder }\end{array}$ & $\$ 20.00$ & 27 & $3.60 \%$ \\
\hline Geologic History of Utah & Lehi Hintze & $\$ 29.95$ & 23 & $3.06 \%$ \\
\hline Geology of Utah & William Lee Stokes & $\$ 17.95$ & 19 & $2.53 \%$ \\
\hline $\begin{array}{l}\text { The Geology of the Parks, } \\
\text { Monuments, \& Wildlands, } \\
\text { of Southern Utah }\end{array}$ & Robert Fillmore & $\$ 23.95$ & 18 & $2.40 \%$ \\
\hline $\begin{array}{l}\text { The Colorado Plateau: A } \\
\text { Geologic History }\end{array}$ & Donald L. Baars & $\$ 26.95$ & 15 & $2.00 \%$ \\
\hline $\begin{array}{l}\text { Beyond the Visible } \\
\text { Landscape }\end{array}$ & W. Kenneth Hamblin & $\$ 58.95$ & 12 & $1.60 \%$ \\
\hline $\begin{array}{l}\text { Geology of Utah's Parks } \\
\text { and Monuments }\end{array}$ & $\begin{array}{l}\text { Paul B. Anderson and } \\
\text { Thomas C. Chidsey }\end{array}$ & $\$ 35.95$ & 11 & $1.46 \%$ \\
\hline $\begin{array}{l}\text { Ancient Landscapes of the } \\
\text { Colorado Plateau }\end{array}$ & $\begin{array}{l}\text { Ron Blakey and Wayne } \\
\text { Ranney. }\end{array}$ & $\$ 35.95$ & 10 & $1.33 \%$ \\
\hline Roadside Geology of Utah & $\begin{array}{l}\text { Felicie Williams and Lucy } \\
\text { Chronic }\end{array}$ & $\$ 20.00$ & 9 & $1.20 \%$ \\
\hline
\end{tabular}

Table 1.2 Shows the percentage of each book sold in the visitor center during 2011-2013. Information courtesy of Shirley Torgerson, Capitol Reef Natural History Association.

As we made plans for Exploring the Diverse Geology of Capitol Reef National Park, I accounted for our goal of creating an accurate and educational book. But we also wanted to make this book interesting and engaging to the visitors of Capitol Reef National Park. After reading reviews of similar books, I found that over-simplifying could be more detrimental than helpful. We purposely used geologic vocabulary and provided an illustrated glossary to satisfy those wanting an intellectual challenge. To align our book with suggestions found in other book reviews, we were careful to write meaningful captions on figures and diagrams, include our best photography, use simple design, provide maps of discussed locations, organize chapters meaningfully, and provide an overview of foundational geologic principles.

\section{Cognitive Load Theory}

Effective instructional typography and typesetting allow readers to glean information with the least amount of mental effort so that they can learn and retain new information more 
efficiently. Typography deals with how the actual type on a page is arranged. This includes the font, font size, line length and justification, line spacing, etc. Typesetting involves the arrangement of the entire page. This includes text, photos and figures, titles, subtitles, etc. Poor typography or typesetting can negatively influence the reader's ability to learn.

Cognitive Load Theory (CLT) is a theory of educational psychology that addresses the work or "cognitive load" of the brain and how to lessen that load, especially during the learning process (Plass et al., 2010). CLT considers the capabilities and limitations of the human cognitive structure to predict schema acquisition. Schema acquisition is the process of organizing and perceiving new information.

There are three types of cognitive load: intrinsic load, extraneous load, and germane load (Fig 1.1). Intrinsic load is generated by the inherent difficulty of the material being learned and the number of elements that are being processed simultaneously by the learner. Since learning difficulty is somewhat relative, this load also depends upon the learner's prior knowledge. Intrinsic load cannot be reduced by the design of the material. Extraneous load, however, is produced by the design of the instructional materials, making it totally alterable by the designer. Ideally, extraneous load should be as limited as possible. Germane load dedicates cognitive resources to processing and constructing schemas rather than using those resources for other mental tasks. The designer can also manipulate germane load, but in this case, the designer wants to promote or increase it. If these three loads are more than the total working memory capacity (the brain's capacity to store and manipulate information), learning cannot occur (Paas et al., 2003). 


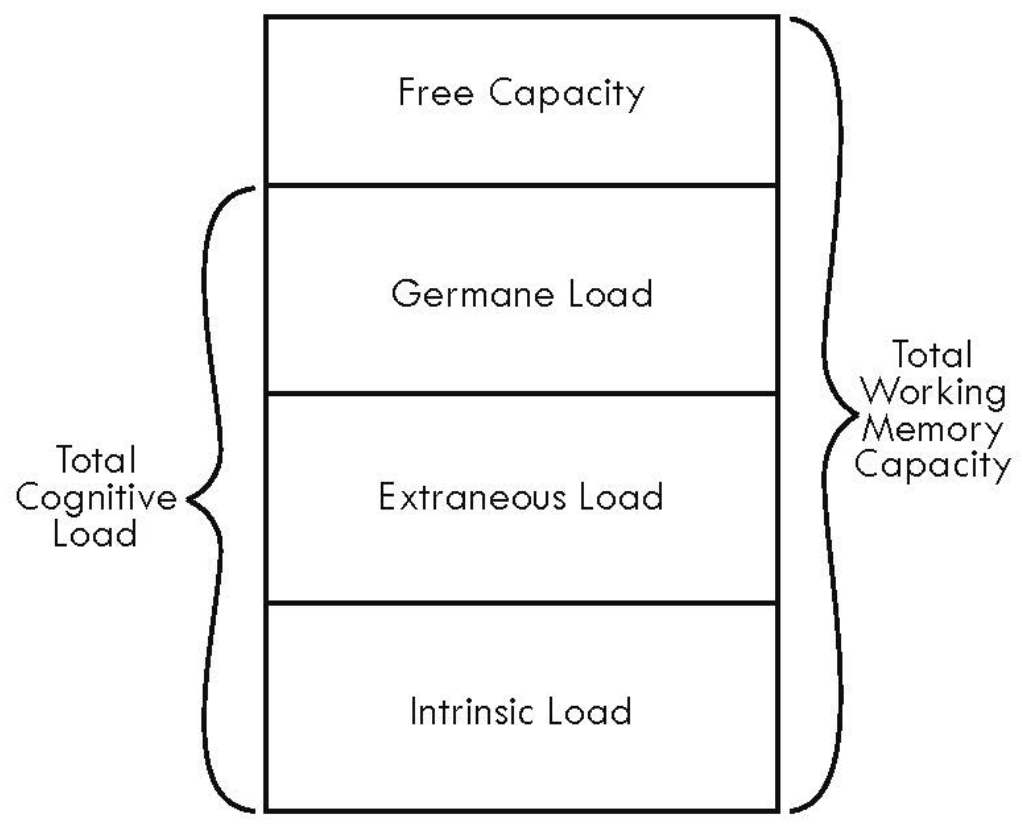

Fig 1.1 The total cognitive load is made up of intrinsic load, extraneous load, and germane load. When the combined total of these three is less than the total working memory capacity, learning can take place (Paas et al., 2003).

Intrinsic, extraneous, and germane load should not exceed total working memory capacity, but loads may be adjusted for the specific learning situations. For example, if new material has high intrinsic load due to its inherent difficulty and/or the lack of prior knowledge of the learner, reducing extraneous load is particularly important to preserve the cognitive resources necessary to learn. Conversely, if intrinsic load is low, reducing extraneous load is not as essential.

\section{Reducing Extraneous Cognitive Load}

Because reducing extraneous load is within the reach of this project, we will focus on usable techniques to accomplish this objective. Four possible sources of extraneous cognitive load are listed below. We also describe how we addressed those potential sources as we wrote and designed Exploring the Diverse Geology of Capitol Reef National Park. 
1. The learner is lacking sufficient foundational knowledge and is not being provided adequate instructional direction. This forces the learner to search for solutions outside of the given instruction.

The preface to Exploring the Diverse Geology of Capitol Reef National Park guides the reader in how to use the book by outlining its organization. The introductory chapter also explains some foundational geologic principles. Bolded words indicate that a simple (and perhaps illustrated) definition is included in the glossary in the back of the book. Our intent was to ensure that the reader would have the necessary tools to understand everything in the book, regardless of previous experiences with geology.

2. Overlap of available knowledge and instructional guidance that forces the learner to establish connections between representations of the same information. This takes away from cognitive resources that could be used to construct new representations.

We avoided using multiple ways to present the same information. The reader can focus on learning foundational concepts and connecting them with further knowledge, rather than making multiple references to the same information. For example, if we used a figure to depict a concept, we only included one. There are quite a few figures in the glossary that are not repeated or re-represented elsewhere.

3. The learner is required to take unnecessarily large or excessive steps to transfer from one concept to the next. Essentially there is too much new information for the working memory to hold and integrate it into long-term memory. 
We arranged the book so the reader could develop foundational concepts at the beginning (Part One) and then build upon those principles in later chapters (Part Two). We made a conscious effort to transition from one topic to another and relate new information to previously learned principles, so as to not overwhelm the reader with new concepts too quickly. For example, the introduction of Chapter 2 explains how different climates affect depositional systems and determine the resulting rock types. We then describe the nineteen geologic formations in Capitol Reef and how climates impacted each rock type during their creation.

4. Instructional representations of related information are separated by time or space, forcing the learner to needlessly search for and match the corresponding material (Plass et al., 2010).

In our book, almost all of the figures and photos are found on the same page as the corresponding text. In two instances, a photo is on the next page due to space limitations. But otherwise, figures and photos are spatially close to their correlative textual explanation.

Science of Learning. Clark and Mayer (2011) developed several principles designed to reduce extraneous cognitive load and help the learner manage intrinsic cognitive load. Although some of their principles were made specifically for multimedia learning environments such as video or online learning, most of the ideas can also successfully be applied to a medium like Exploring the Diverse Geology of Capitol Reef National Park. We implemented the following four principles in the development of this book: 
1. The Coherence Principle states that adding too many words or graphics can inhibit learning. The designer should avoid using material that does not support learning goals. Extraneous graphics can distract the reader away from material that is relevant to learning. It can also disrupt or prevent the learner from building links between related material because irrelevant material is in the way. In order to implement the coherence principle, the designer should use simple visuals; two dimensional figures are generally more effective than three dimensional (Fig. 1.2). Additional, the author should avoid adding extra words that are technical or go beyond the main ideas of the lesson. Since subject experts are prone to over explain and use vocabulary specific to their field, we made a conscious effort to use straightforward but not oversimplified wording.

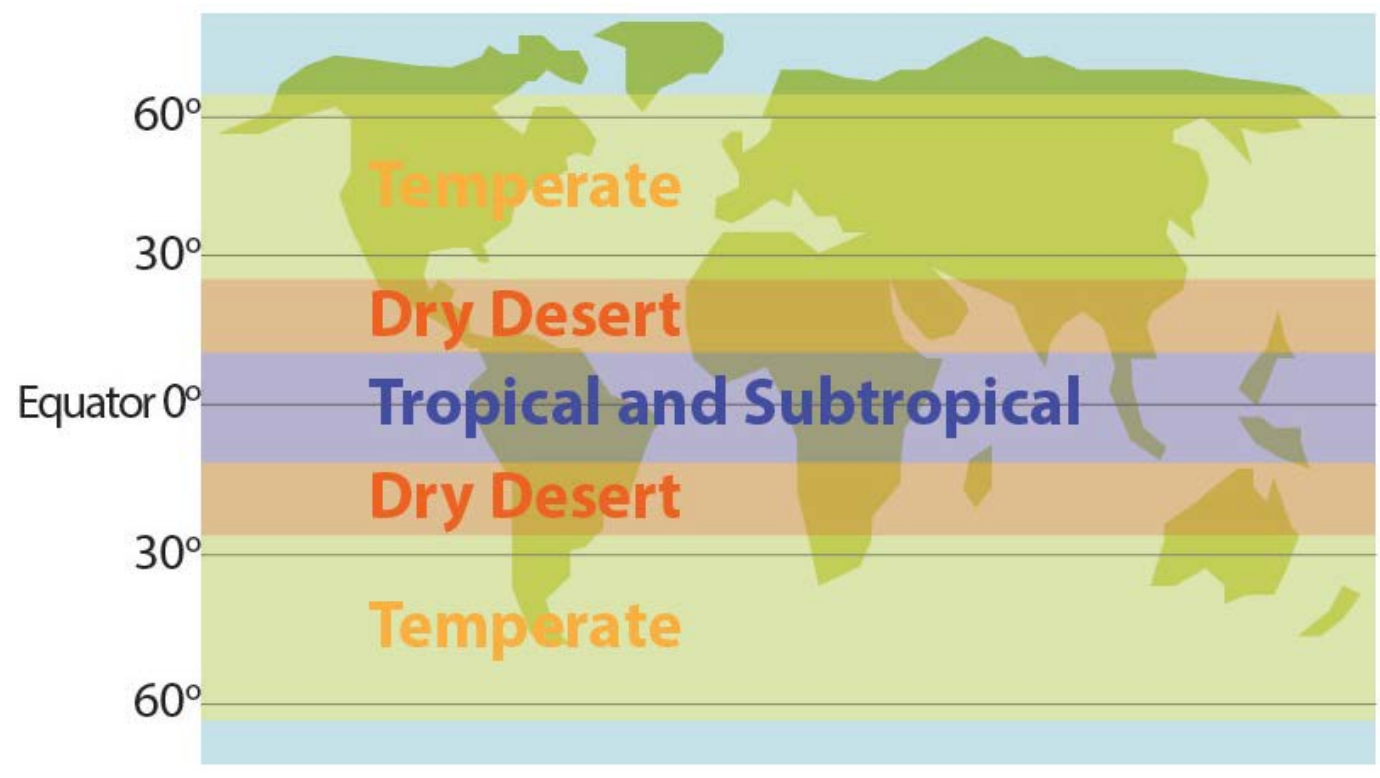

Figure 1.2 This two dimensional world map has no continent, country, or other labels. It is simply overlain by the colored climatic belts. Rather than listing the specific latitudes associated with each belt in a caption, they are pictured on the map so the reader can visually relate the climate belts with their respective regions.

2. The Contiguity Principle deals with how words and graphics are laid out on the page (or screen, if online). Words should be arranged with corresponding graphics. When possible, labels should be placed near the corresponding parts of figures or diagrams, not 
as a caption at the bottom. This prevents the learner from jumping back and forth from graphic to caption (Fig 1.3).

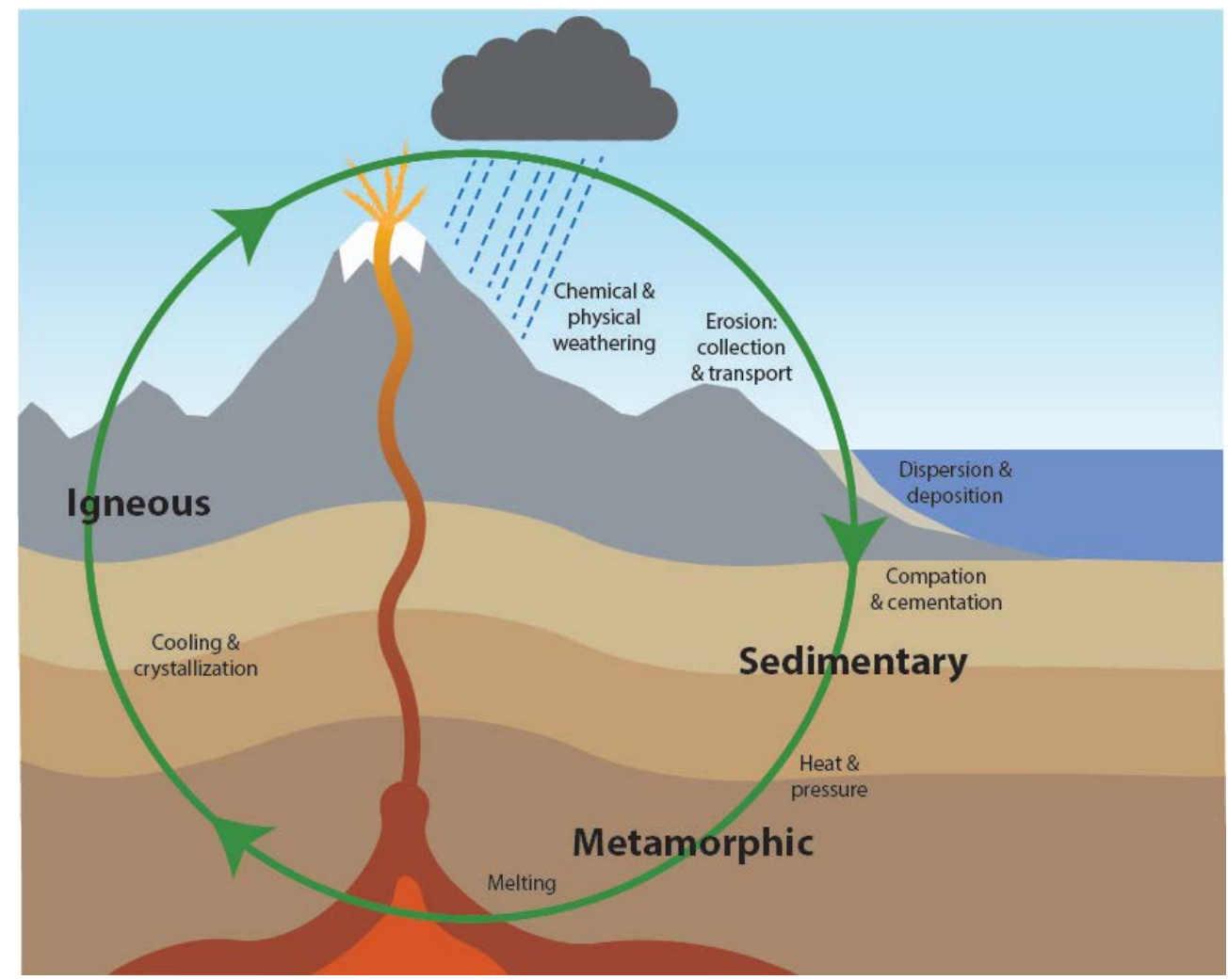

Figure 1.3 The rock cycle and steps in between each rock type are simply listed on the actual figure, rather than the caption. The reader can grasp the rock cycle without much further explanation. However, we did include a caption as well to provide further clarification if needed.

3. The Multimedia Principle encourages using words and graphics rather than only words.

This promotes making connections between textual and visual representations of new concepts. Those connections lead to a deeper understanding of the material. However, graphics should support learning by showing relationships between two or more variables, showing changes over time, organizing relatable material, or showing invisible relationships or movements (Fig. 1.4). Graphics that are decorative or show only one element should be kept to a minimum. 


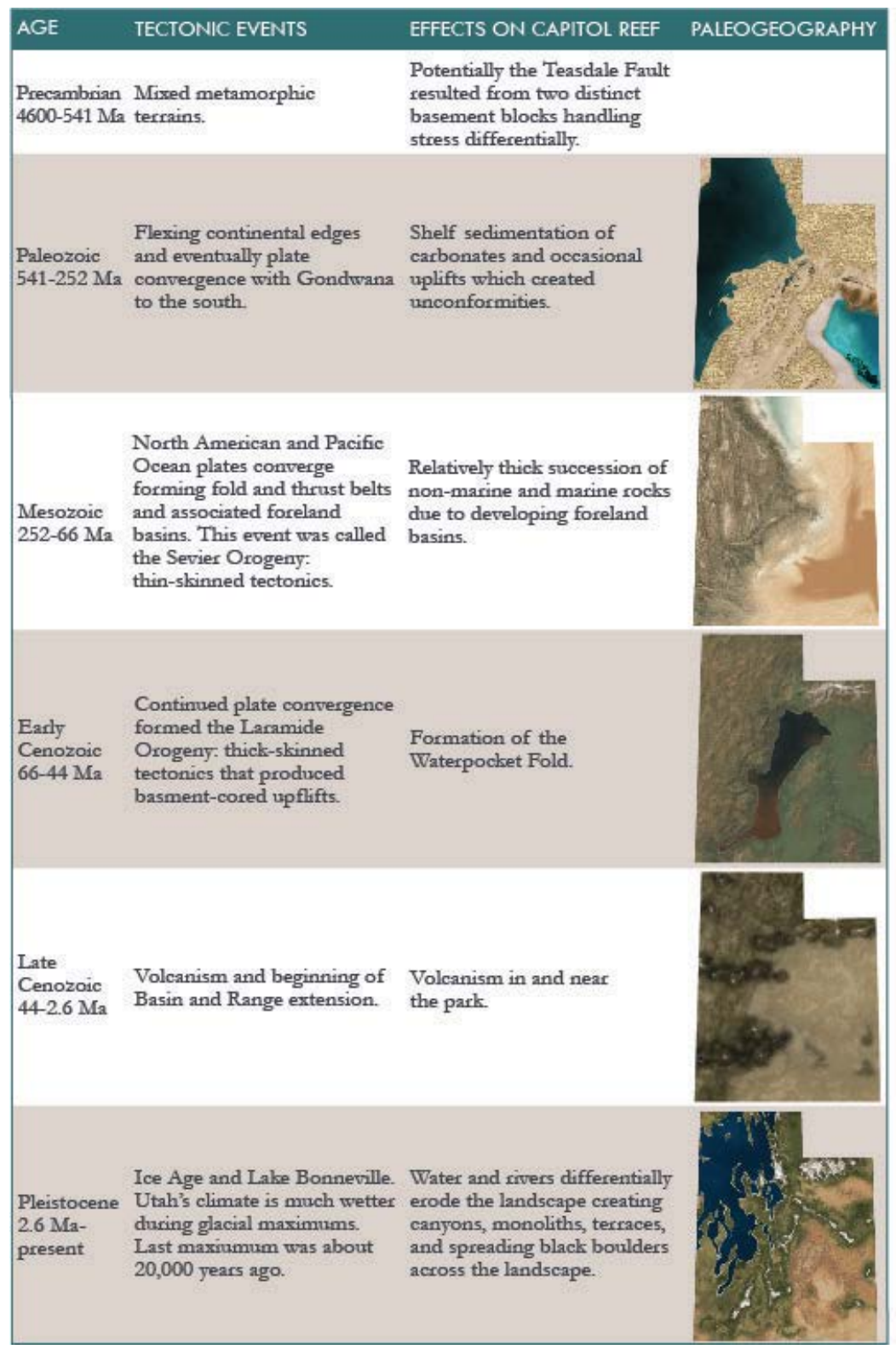

Figure 1.4 This chart exhibits major tectonic events and how they affected Capitol Reef. It uses both text and graphics to show how tectonic forces influenced Utah's topography and climate over geologic time. The evolution of Utah's landscape is easily visualized in one figure.

4. The Segmenting Principle deals with breaking a lesson or concept into parts. This breaks intrinsically heavy concepts into more manageable pieces. This may also involve teaching the learner some foundational vocabulary or ideas before the lesson. 
Although many will be educated, most readers of this book will not have a background in geology. In the introductory chapter, we explain some fundamentals of geology and explain key terms. The chapter includes how landscapes are formed by plate tectonics, weathering and erosion, bedrock strata, and deformation of that strata. We further explain how plate tectonics has influenced Utah's geology and refer back to those concepts many times in subsequent chapters. Because the Waterpocket Fold is the centerpiece of the park, we explain what it is and how it happened. We include a stratigraphic column and show how to use it. Many words are also included in the illustrated glossary which are indicated by a bold typeface. Subsequent chapters include concepts that are built upon these foundational principles.

\section{Instructional Typography}

James Hartley (1994) has done extensive research on instructional design and typography. Hartley emphasizes the importance of planning before actually designing instructional text. How, when and where the document will be used should influence its weight, size, orientation, binding, storage, and cost. Hartley suggests using pages sizes that have 1: $\sqrt{2}$ ratios for more efficient printing and storage, hence this book has dimensions of 180:255 $\mathrm{mm}$. He also found that line spacing should be about 1.25 times the type size and in general, text should be 10-12 point. We used 10 point font for the body of the text and 9.5 point for figure captions. Line spacing was 12 point for body text and 10 point for captions. Text should not be fully justified and paragraphs should be separated by a line rather than indentation, both of which we implemented in the body of the text throughout the book (Hartley and Burnhill, 1977). Margins should be $10 \mathrm{~mm}$ at the top and bottom and $20 \mathrm{~mm}$ at the left and right (Hartley, 1986). The use of white space helps readers to feel less cluttered and increases the ease with which they 
can follow the flow of the page to retrieve and understand new information (Hartley, 1994). With the exception of pages that are full photos, all pages in Exploring the Diverse Geology of Capitol Reef National Park have white space between paragraphs, around photos, and around the margins. Typographical cueing such as underlining, italics, capitals, etc. can be helpful to draw attention to specific words or phrases, but these cues should be kept to a minimum. Bold words should ideally be used to indicate words included in the glossary (Hartley, 1986). We included 96 bolded words throughout the text of the book which are included in the illustrated glossary.

Hartley (1994) also researched how to write instructional text. He encouraged helping the reader make connections between new information and prior knowledge, asking questions within the text or even in the headings and subheadings (Brian, 1989). Hartley also encouraged using familiar or conversational language rather than technical terms. He found that using verbal descriptions of numbers are better than the actual numbers. For example, using "nearly half of the samples" instead of the actual number. Lists should be in bulleted or numbered lists, not in paragraph form. Overuse of numbers, may be confusing, but they are appropriate for chapter numbers, pages, and figure numbers. Page numbers should be placed on the outside corner of the page so they can be easily seen when flipping through the book. Using short sentences (usually with just one subordinate clause) should be given preference over longer sentences. He also discussed the importance of avoiding footnotes so as to avoid breaking up the flow of reading.

We used Hartley's (1994) suggestions in our text. For example, rather than speaking to "the reader," we used pronouns such as "you" and "we" to make the text more conversational and less like a scientific paper. We also asked headings in the chapter subtitles such as "What is a monolith?" and "What are those black boulders?" We did not use footnotes anywhere in the 
text. We arranged lists in a bulleted or numbered list rather than in the paragraph. Page numbers are on the corners of the pages.

\section{Was the Effort Guided by Design?}

We completed the goals set in the context step by utilizing plans identified in the input step successfully, although not within the timeline originally listed in my prospectus. It was especially important to find an effective organization for the book. Even with excellent content and design, if the information is not presented in a logical order, readers may become confused or frustrated. Pre-planning the organization, layout, page size, writing style, text size and fonts, helped us achieve the goals we set in the context step with minimal changes.

\section{PROCESS}

The process evaluation asks, "Is it being done?" and, "Was the design executed competently and modified as needed?" This step involved mostly planning a timeline of when we would accomplish specific goals. Although I did not follow my original schedule, I did modify it and set new due dates for myself as we worked on this project. I did complete the tasks listed in my prospectus timeline in order, just not on the listed dates.

\section{Is it Being Done?}

Although we completed the tasks set in our original timeline in order, they did not happen when we anticipated.

\section{Was the Design Executed Competently and Modified as Needed?}

Throughout the process of writing and designing the book, we kept our goals in mind and modified aspects of our original plans as necessary. For example, we considered several layout/organization options before making a final decision as we considered the needs of our audience. 


\section{PRODUCT}

Making a complete or long-term product evaluation is not within the scope of this project. However, formative and summative evaluations were possible to an extent.

\section{Is it Succeeding?}

Since the first drafts of Exploring the Diverse Geology of Capitol Reef National Park was only available to the authors of the book, we made our own evaluations for most of the project. Our success was based on our original goals set in the context step, and we made adjustments as needed. Several times we finished a chapter or section and then realized a figure or a photo would be helpful. Other instances involved adding words to the glossary, changing or simplifying descriptions, or improving transitions between concepts.

\section{Did the Effort Succeed?}

To perform summative evaluations, I did 18 qualitative interviews of individuals as they reviewed a copy of the book (before final printing). I interviewed mostly non-geologists, but also a few geology students. There were about equal numbers of men and women. Interviewees were between the ages of 20 and 63 with education levels ranging from some college to $\mathrm{PhD}$ (Fig. 1.5). I instructed the interviewees to skim through the entire book and then pick a section or two that looked interesting to them and read it more in depth. Once they were finished, I asked them what they thought about the size of the book, how they would use it, the level of difficulty of the text, the organization, the glossary, and how likely they would be to buy it. 


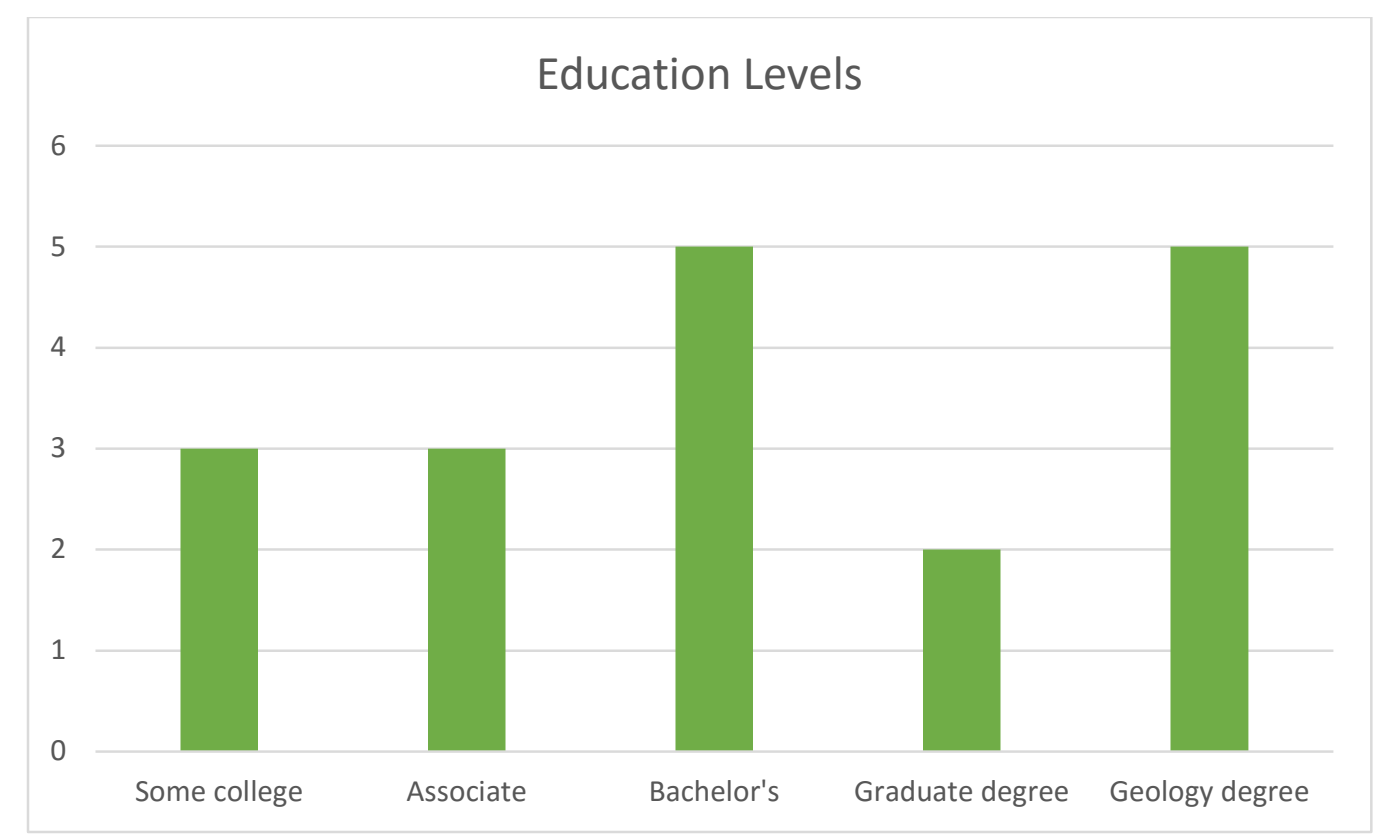

Figure 1.5 Interviewees ranged in education levels from some college to graduate degrees, with some geologists included.

Size

Most interviewees thought the size was appropriate for this book (Fig. 1.6). Our intent for this book is for readers to take it with them in the park. Therefore, we were pleased that our interviewees thought it was a perfect size to bring in a backpack. Without seeing the book with a cover, some assumed it was a coffee table style book, in which case they thought making it slightly bigger might be better. Two individuals also mentioned making an accompanying pocket-sized guide booklet/pamphlet to use while in the park. However, those that saw it originally as a guidebook to use while in the park thought it was a suitable size. 


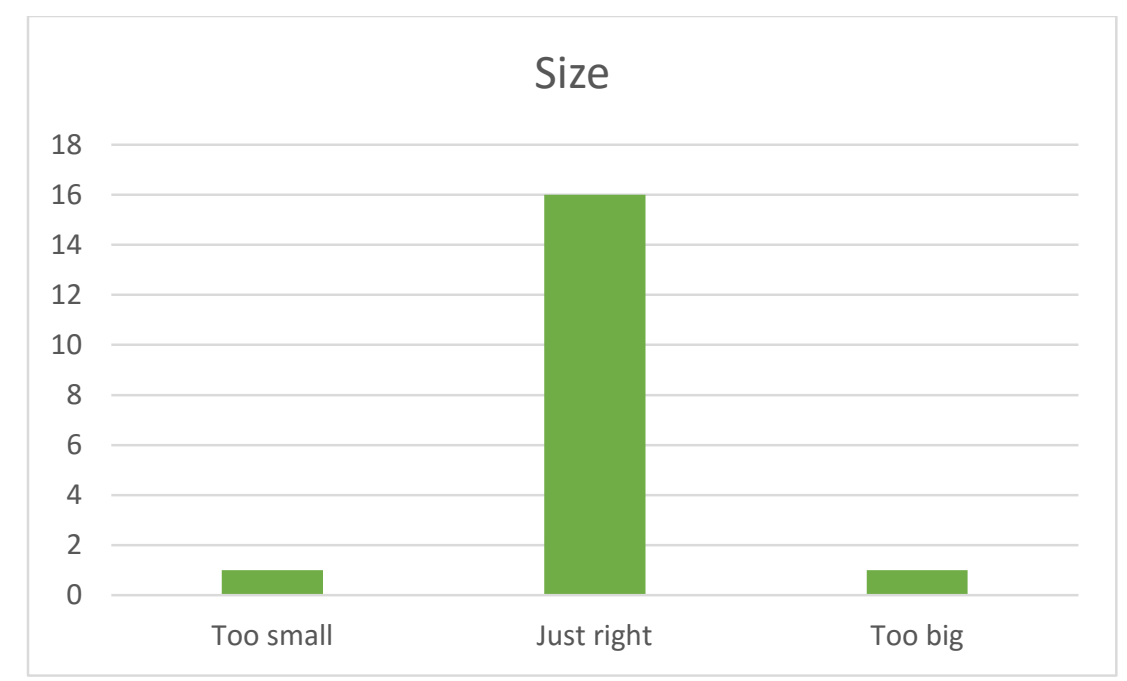

Figure 1.6 Almost all interviewees thought the size of the book was appropriate for its intended use.

Use

Readers suggested using this book in a variety of ways (Fig. 1.7). All interviewees stated they would use the book at home before or after a trip to Capitol Reef, or while on a trip to Capitol Reef as a guidebook, or both. A college professor said it would be a great guide to use as he takes his students to Capitol Reef every semester. One mother mentioned using it as a homeschooling resource and then taking her kids to the Capitol Reef on a field trip.

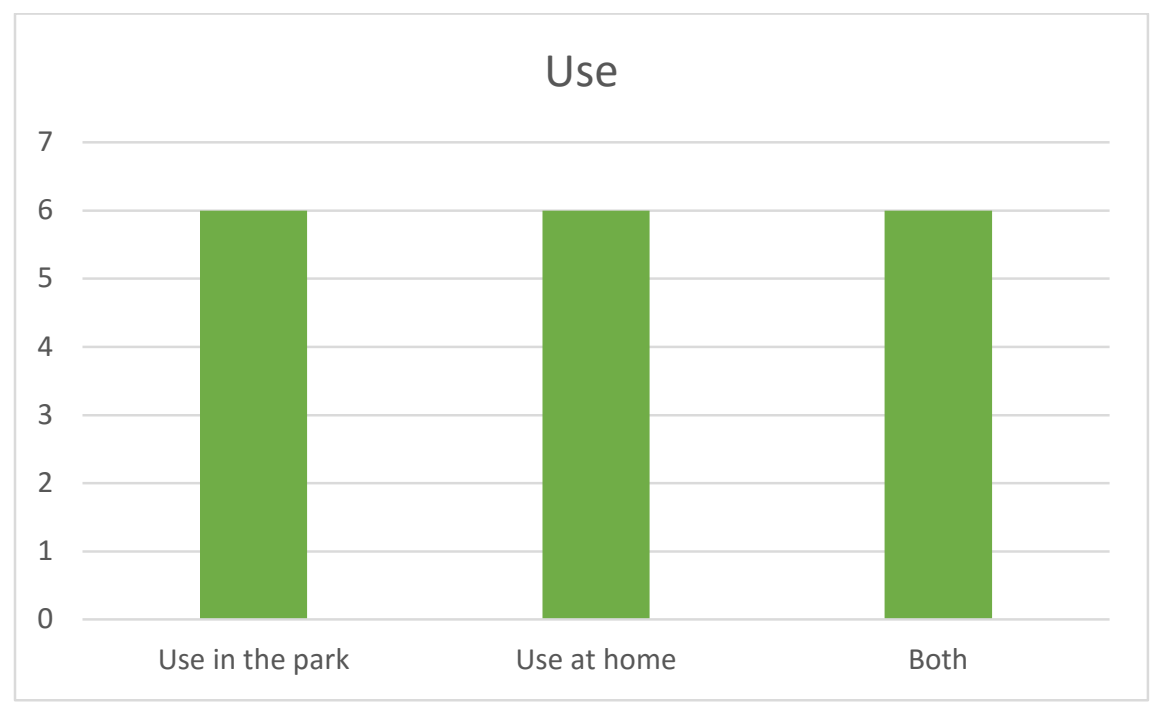

Figure 1.7 Readers found a range of settings for the book including use in the park, at home, or both. 


\section{Difficulty}

Most people were comfortable with the level of difficulty of the text (Fig. 1.8). Although 5 interviewees expressed the difficulty level as challenging, they all welcomed the task of learning new vocabulary and concepts and said it did not hinder their enjoyment. One reader mentioned that in some instances there was more information than she thought necessary, but it was still understandable. One man said that the readers will definitely need to be educated; it may be a challenge for high school level visitors, or even some college students. However, we designed Exploring the Diverse Geology of Capitol Reef National Park to be used by our target audience of college educated individuals, so the reading level is appropriate.

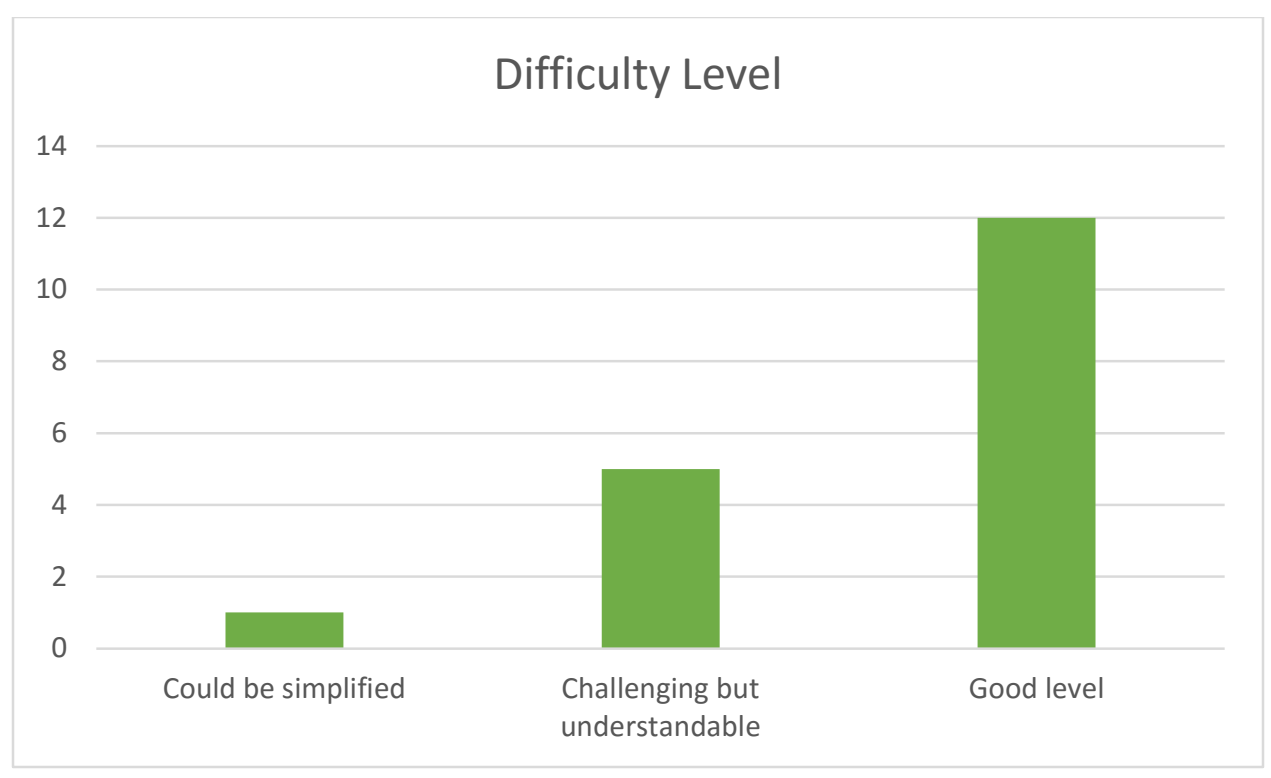

Figure 1.8 Almost all interviewees said they could understand the text. Five expressed it as a challenge, but most were comfortable with the difficulty level. One stated that it could be simplified more.

\section{Organization}

All of the interviewees thought the organization of the book flowed well. They thought it made sense to start with foundational geologic principles, and then describe how those are incorporated into specific sites in the park. One woman said that knowing the background 
information in Part 1 helped her appreciate the geologic features in Part 2 even more. Those that had little background in geology enjoyed having an explanation of the basics before moving on to specific sites.

\section{Glossary}

One of the interviewees' favorite sections was the illustrated glossary. Six people had immediate positive reactions upon seeing the glossary. One individual said the illustrations and photos made the glossary seem less intimidating, and all thought they made the glossary more understandable. Two people suggested adding pronunciation guides to some of the uncommon words.

\section{Buying}

Interviewees had mixed reviews when asked if they would purchase Exploring the Diverse Geology of Capitol Reef National Park (Fig. 1.9). Eight interviewees said they would buy it, and six said they would probably not. Those that said they would not buy it gave reasons such as already knowing the geology, not usually buying books from visitor centers, having a similar book already, or not spending enough time in the park to need it. Three individuals said it would depend heavily on the price. One man said he might be more likely to buy it online before visiting the park. 


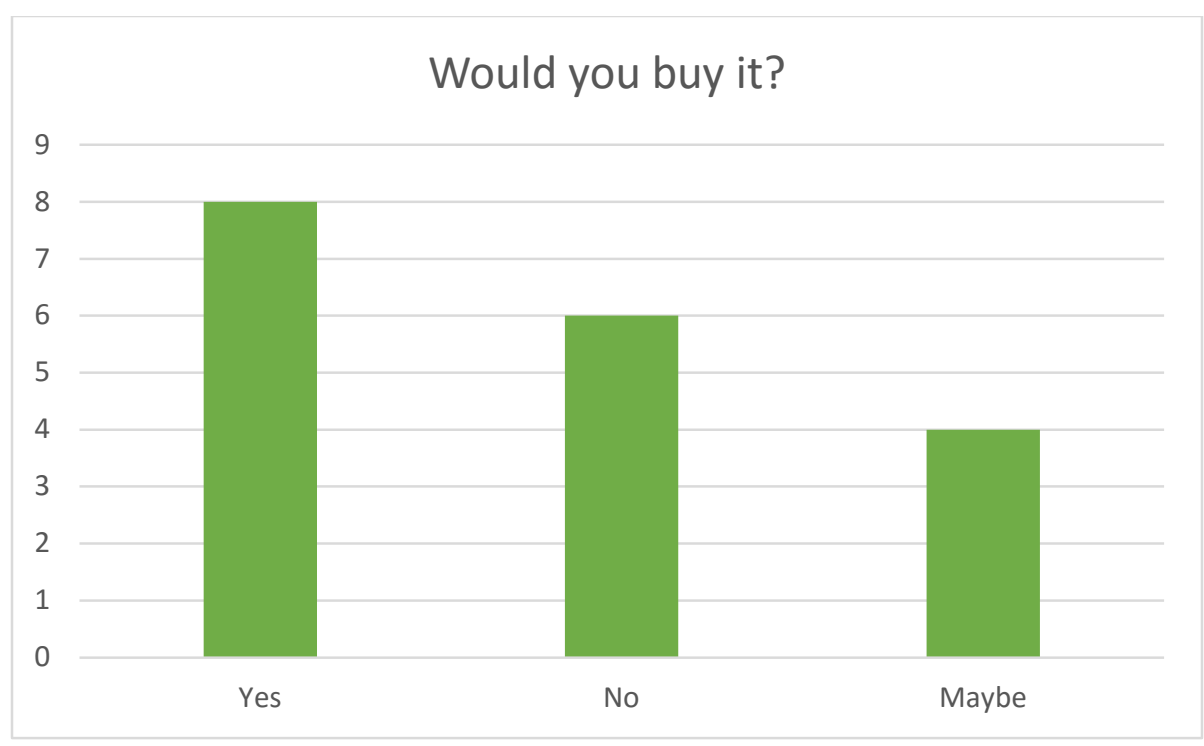

Figure 1.9 Most interviewees said they would be interested in buying the book if they came across it at the Capitol Reef National Park visitor center.

Overall, the interviewees seemed to have a very positive response. Seven individuals specifically mentioned the photographs and design were professionally done and visually appealing. Two people said maps showing locations of specific sites were very helpful. One couple said they will change their summer southern Utah travel plans to include Capitol Reef. Interviewees also helped find sections that could be worded more clearly, which we then corrected. We accomplished our goal of providing an aesthetically pleasing and scientifically accurate book.

\section{CONCLUSION}

The CIPP model enabled us to methodically evaluate our progress and final project while maintaining and achieving our original goals. It was essential that we completed the steps of context, input, process, and product sequentially. The objectives we set in the context step guided our actions throughout the development of the book. Identifying our target audience made subsequent decisions easier and more meaningful. The background research required in the input step made the whole project significantly more successful. After studying instructional design 
techniques and approaches, I have come to realize that printed book design can either hinder or enhance learning. The design tactics implemented in this book have been proven to ease cognitive load and increase learning and retention. Knowing how the human brain learns from words and pictures printed on a page and how to make that learning more effective guided the whole project. We are fortunate to learn from previous studies about what makes learning easier and how we can make simple adjustments to reduce extraneous cognitive load. Everything from font size and spacing to placing annotations on figures helps the mind grasp information. In the process step, we held ourselves accountable for what we set out to do. The product step assured us that the previous three steps indeed led to success. Although Exploring the Diverse Geology of Capitol Reef National Park needed some minor adjustments, suggested by interviewees, before final printing, I was so pleased to see that it was enjoyable to geologists and non-geologists alike as I conducted interviews.

Using a framework for evaluation that included both formative and summative evaluations ensured that we did not stray from our objectives and provided the tools to accomplish them. However, we did face challenges. Since the bulk of the actual writing occurred after our visits to the park, it was difficult to know which photographs were necessary during those visits. Although we tried taking pictures of everything we thought was of note, we did miss a couple. Thankfully, park photographer, Christopher Roundtree, was kind enough to send us one in particular after we realized we were missing a photo of Grand Wash. Although complete prediction is impossible, perhaps more careful planning of the specific chapters and discussions would have helped us know what we needed sooner. Another challenge was knowing how to organize the book before the text was complete. We wrestled with a few ideas before settling on the final layout. But again, knowing our audience and objectives directed our decision. We had a 
basic idea of how we would organize the book, and then realized after writing more that it could be improved. Once we refined our plans regarding the organization of the book, we had only minor adjustments to make as we smoothed transitions from one chapter or topic to another. Continually making formative evaluations such as these throughout the development of the book enhanced its success. After making these and other adjustments along the way, the final product is educationally sound, aesthetically pleasing, and appropriate for its intended use.

My hope is that Exploring the Diverse Geology of Capitol Reef National Park will help park visitors enjoy their visit and educate themselves on the spectacular geology surrounding them. Capitol Reef National Park is an invaluable resource that allows us to peak into Earth's dynamic geologic history. Providing an accessible and accurate geologic publication will help the visitors of Capitol Reef National Park appreciate this truly remarkable location.

Enclosed: disc of final product in PDF format. 


\section{REFERENCES}

Brian, P., 1989, Improving Instructional Print Materials Through Text Design: Performance + Instruction, v. 28, no. 7, p 13-18.

Clark, R.C. and Mayer, R.E., 2011, E-Learning and the Science of Instruction: Proven Guidelines for Consumers and Designers of Multimedia Learning (3rd Edition): Hoboken, New Jersey, Pfeiffer, $527 \mathrm{p}$.

Coble, T.G., Lin, H.S., Coble, D.W., Hart, J.L., Williams, P.S., and Darville, R., 2005, Visitor Voices Project 2005: http://www2.sfasu.edu/msri/Visitor Voices 2005 tech report.pdf (accessed December 2014).

Coble, T.G., Lin, H.S., Coble, D.W., 2009, Visitor Voices Project 2008: file://C:/Users/kinse_000/Downloads/Coble_2008_Visitor_Voices_Study.pdf (accessed December 2014).

Hartley, J. and Burnhill, P., 1977, Fifty Guide-Lines for Improving Instructional Text: Innovations in Education \& Training International, v. 14, no. 1, p. 65-73.

Hartley, J., 1986, Planning the Typographical Structure of Instructional Text: Educational Psychologist, v. 21 , no. 4 , p. $315-332$.

Hartley, J., 1994, Designing Instructional Text (3rd Edition): East Brunswick, New Jersey, Nichols, 184

Paas, F., Renkl, A., \& Sweller, J. (2003). Cognitive load theory and instructional design: Recent developments. Educational Psychologist, 38, 1-4.

Plass, J.L., Moreno, R., and Brünken, R., 2010, Cognitive Load Theory: New York, Cambridge University Press, 275 p. 
Stufflebeam, D.L. and Shinkfield, A.J., 2007, Evaluation Theory, Models, and Applications: San Francisco, California, Jossey-Bass, 768 p. 